\title{
Optimizing the treatment of bevacizumab as first-line therapy for human epidermal growth factor receptor 2 (HER2)-negative advanced breast cancer: an updated meta-analysis of published randomized trials
}

This article was published in the following Dove Press journal:

OncoTargets and Therapy

27 June 2017

Number of times this article has been viewed

\author{
Cunfu Li' \\ Aizhai Xiang ${ }^{2}$ \\ Xianzhi Chen ${ }^{3}$ \\ Kai Yin ${ }^{4}$ \\ Jinsong $\mathrm{Lu}^{4}$ \\ Wenjin Yin ${ }^{5,6}$ \\ 'Department of General Surgery, \\ Weihai Central Hospital, Weihai, \\ ${ }^{2}$ Department of Breast Surgery, \\ Hangzhou First People's Hospital, \\ Nanjing Medical University, Hangzhou, \\ ${ }^{3}$ Department of General Surgery, \\ Huainan First People's Hospital, \\ Huainan, ${ }^{4}$ Department of Breast \\ Surgery, Renji Hospital, School \\ of Medicine, Shanghai Jiao Tong \\ University, ${ }^{5}$ Department of Breast \\ Surgery, Fudan University Shanghai \\ Cancer Center, ${ }^{6}$ Department \\ of Oncology, Shanghai Medical \\ College, Fudan University, Shanghai, \\ People's Republic of China
}

Background: Manifold data have demonstrated that the addition of bevacizumab to chemotherapy improved progression-free survival (PFS), while few trials have revealed its significant overall survival (OS) benefit. Furthermore, it still remains suspended how to maximize the benefits of bevacizumab as first-line therapy for human epidermal growth factor receptor 2 (HER2)-negative breast cancer. We sought to conduct a meta-analysis to assess the benefits of bevacizumab with chemotherapy and to identify the ideal chemotherapy partner of bevacizumab in the first-line setting for HER2-negative advanced breast cancer patients.

Methods: Computerized and manual searches were performed to identify randomized clinical trials evaluating the efficacy of bevacizumab plus chemotherapy versus chemotherapy alone or bevacizumab with different chemotherapy regimens as first-line therapy for HER2-negative locally recurrent or metastatic breast cancer patients. Risk ratios or odds ratios with their $95 \%$ CIs were used to estimate the association between multiple combinations of bevacizumab with chemotherapy and various clinical outcomes.

Results: With 7 trials identified, this analysis included 3,984 eligible patients. The addition of bevacizumab to chemotherapy resulted in a statistically significant improvement in PFS $(P=0.019)$ and objective response rate (ORR; $P<0.001)$ rather than in OS $(P=0.783)$ when compared with chemotherapy alone. The greater benefits in PFS and ORR were achieved from bevacizumab plus taxane-based regimens compared with bevacizumab plus capecitabine-based regimens, while bevacizumab plus capecitabine had comparable OS with bevacizumab plus paclitaxel. Additionally, bevacizumab-based triplet therapy failed to improve the clinical outcomes when compared with doublet therapy.

Conclusion: This meta-analysis reveals that the addition of bevacizumab to chemotherapy yielded PFS and ORR benefits in HER2-negative advanced breast cancer. Additional studies are still prompted to further optimize the first-line treatment of bevacizumab.

Keywords: breast cancer, bevacizumab, first-line, HER2-negative, meta-analysis

\section{Introduction}

Breast cancer is the most common cancer that affects women worldwide. Although its prognosis has been greatly improved due to the rapid development of multidisciplinary therapy, breast cancer still remains the second leading cause of cancer-related 
deaths, the main reasons of which are disease progression and therapeutic resistance. ${ }^{1}$ Recent investigations have revealed that angiogenesis contributes to the progression of breast cancer, and the overexpression of vascular epithelial growth factor (VEGF) promotes its proliferation and metastasis..$^{2-8}$

Bevacizumab, a humanized recombinant monoclonal antibody that specifically targets VEGF receptors (VEGFRs), has become a promising agent for the treatment of metastatic breast cancer. ${ }^{9}$ Indeed, this agent has attracted much spotlight because of several controversial issues. In 2008, the US Food and Drug Administration (FDA) granted accelerated approval to bevacizumab in combination with the paclitaxel as firstline therapy for human epidermal growth factor receptor 2 (HER2)-negative metastatic breast cancer patients. This rapid approval was based on the positive results from the E2100 trial. ${ }^{10}$ However, in 2010, the FDA finally decided to revoke the approval of bevacizumab for this indication. On the other hand, the European Medicines Agency reaffirmed its approval of the drug for the same indication. ${ }^{11}$ Both agencies based their decisions on the same data from the subsequent AVADO and RIBBON-1 trials. ${ }^{12,13}$ These 2 trials demonstrated that the addition of bevacizumab to chemotherapy improved the progression-free survival (PFS) in HER2negative metastatic breast cancer patients, while neither of them revealed statistically significant overall survival (OS) benefit. To date, the efficacy of bevacizumab is still hotly debated. Furthermore, there are no clear answers on how to maximize the benefits of bevacizumab as first-line therapy for HER2-negative breast cancer.

Therefore, we conducted a meta-analysis of all eligible studies to address the overall benefits of bevacizumab as first-line therapy in HER2-negative advanced breast cancer. Additionally, we aimed to determine the best combination of bevacizumab and chemotherapy in such setting.

\section{Methods}

\section{Search strategy}

The keywords "bevacizumab" or "Avastin", "phase III" or "phase 3" and "breast cancer" were employed to search the PubMed, Web of Science, EMBASE and EBSCO databases from January 2000 to March 2017 for relevant randomized controlled clinical trials published in English. The selection of the included publications was independently performed by 2 experienced authors (Cunfu Li and Aizhai Xiang). The reference lists of textbooks, previous reviews and all retrieved articles were scrutinized to identify additional studies with potential eligibility. Abstracts, conference information, editorials, letters and case reports were excluded.

\section{Eligibility criteria}

We evaluated the full article of each relevant study and included 7 phase III randomized controlled trials that evaluated the efficacy of combining bevacizumab with chemotherapy versus chemotherapy alone or combining bevacizumab with different chemotherapy regimens as first-line therapy for HER2-negative locally recurrent or metastatic breast cancer. Phase I, phase II and nonrandomized studies were excluded. Trials were considered ineligible if they recruited patients to assess neoadjuvant or adjuvant bevacizumab or to evaluate bevacizumab with other target therapies. For multiple reports of the same cohort, the most recent publication was chosen for this analysis.

\section{Data extraction}

Data were extracted from eligible publications independently by 2 authors (Xianzhi Chen and Kai Yin). Discrepancies were discussed with a third author (Jinsong Lu), and agreements were reached with consensus according to the Quality of Reporting of Meta-Analyses guidelines. ${ }^{14}$

The following data were extracted from all selected articles: first author, publication year, sample size, number of patients in each arm, bevacizumab and chemotherapy regimens, and either the number of endpoint events in each arm or hazard ratios (HRs) with $95 \%$ CIs in each arm.

\section{Statistical analysis}

In this meta-analysis, the primary endpoint was PFS, defined as the time from the date of randomization to the date of first documented disease progression or death. The secondary endpoints included OS and objective response rate (ORR), defined as the time from the date of randomization to the date of death from any cause and the percentage of patients who achieved a complete or partial response confirmed $\geq 28$ days after initial documentation of response.

The risk ratio (RR) with its 95\% CI was calculated for PFS and OS, while the odds ratio (OR) with 95\% CI was calculated for ORR. For the trials with only HRs available, the HRs were used as RRs to facilitate the calculation. The heterogeneity of the study outcomes was calculated using Cochran's $Q$ statistics ( $\chi^{2}$ test) and $I^{2}$ test. Either a $P$-value $<0.05$ or $I^{2}>50 \%$ was considered as statistically significant heterogeneity, which indicated the use of a random-effects (DerSimonian and Laird method) model. If there was no between-study heterogeneity, a fixed-effects (MantelHaenszel method) model was applied. ${ }^{15}$

Publication bias was evaluated using funnel plots and Begg's test. Sensitivity analyses were performed to 
quantify the impact of individual trials on the overall effect. A two-sided $P$-value $<0.05$ was considered significant. All statistical analyses were conducted with Stata statistical software package (release 12.0; Stata Corporation, College Station, TX, USA).

\section{Results}

\section{Characteristics of eligible trials}

Considering the quality of the data, we included all the potentially eligible phase III randomized clinical trials with available information for the target population. Based on the search strategy, 7 eligible trials with a total of 3,984 patients were identified and included in this meta-analysis (Figure S1). ${ }^{12,13,16-20}$ The details of these included studies are summarized in Table 1. Three of these studies were used to evaluate the efficacy of adding bevacizumab to chemotherapy, including 1,558 women who received bevacizumab combined with chemotherapy and 896 women who were administered chemotherapy alone. ${ }^{12,13,17}$ The other 4 trials were obtained to assess the optimal chemotherapy partner of bevacizumab. ${ }^{16,18-20}$ All of them were published as full articles and described as Phase III randomized controlled trials. The former 3 trials were double blinded, ${ }^{12,13,17}$ and the latter 4 studies were open label. ${ }^{16,18-20}$ Of note, the E2100 trial was considered ineligible for this meta-analysis despite its inclusion in the

Table I Characteristics of eligible studies

\begin{tabular}{|c|c|c|c|}
\hline Study name & Arms of the study & Primary endpoint & Secondary endpoint \\
\hline AVADO & $\begin{array}{l}\text { Bevacizumab } 7.5 \mathrm{mg} / \mathrm{kg} \text { plus docetaxel } \\
100 \mathrm{mg} / \mathrm{m}^{2} \text { (day I); bevacizumab I } 5 \mathrm{mg} / \mathrm{kg} \text { plus } \\
\text { docetaxel } 100 \mathrm{mg} / \mathrm{m}^{2} \text { (day I); placebo plus } \\
\text { docetaxel } 100 \mathrm{mg} / \mathrm{m}^{2} \text { (day I); every } 3 \text { weeks }\end{array}$ & Progression-free survival & $\begin{array}{l}\text { Best overall response, duration of } \\
\text { response, time to treatment failure, } \\
\text { overall survival, safety, quality of life }\end{array}$ \\
\hline RIBBON-I & $\begin{array}{l}\text { Bevacizumab I } 5 \text { mg/kg (day I) plus } \\
\text { chemotherapy; placebo (day I) plus } \\
\text { chemotherapy; every } 3 \text { weeks }\end{array}$ & Progression-free survival & $\begin{array}{l}\text { Overall survival, I-year survival rate, } \\
\text { objective response rate, duration of } \\
\text { objective response, progression-free } \\
\text { survival based on independent review } \\
\text { committee assessment, safety }\end{array}$ \\
\hline MERiDiAN & $\begin{array}{l}\text { Bevacizumab } 10 \mathrm{mg} / \mathrm{kg} \text { (days I, I5) plus } \\
\text { paclitaxel } 90 \mathrm{mg} / \mathrm{m}^{2} \text { (days I, 8, I5); placebo } \\
\text { (days I, I5) plus paclitaxel } 90 \mathrm{mg} / \mathrm{m}^{2} \\
\text { (days I, 8, I5); every } 4 \text { weeks }\end{array}$ & $\begin{array}{l}\text { Investigator-assessed progression- } \\
\text { free survival in the intent-to-treat } \\
\text { and pVEGF-A } A_{\text {high }} \text { populations }\end{array}$ & $\begin{array}{l}\text { VEGF-A-by-treatment interaction test } \\
\text { for progression-free survival in the } \\
\text { intent-to-treat population, investigator- } \\
\text { assessed objective response rate in } \\
\text { patients with measurable disease at } \\
\text { baseline, duration of objective response } \\
\text { in responding patients with measurable } \\
\text { disease at baseline, overall survival, } \\
\text { I-year overall survival rate, safety }\end{array}$ \\
\hline TABEA & $\begin{array}{l}\text { Bevacizumab } 15 \text { mg/kg (day I) plus taxanes/ } \\
\text { capecitabine; bevacizumab } 15 \text { mg/kg (day I) } \\
\text { plus taxanes; every } 3 \text { weeks }\end{array}$ & Progression-free survival & $\begin{array}{l}\text { Response rate and duration, } \\
\text { clinical benefit rate, 3-year overall } \\
\text { survival, progression-free survival } \\
\text { in patients aged } \geq 65 \text { years, toxicity, } \\
\text { compliance }\end{array}$ \\
\hline SAKK 24/09 & $\begin{array}{l}\text { Bevacizumab } 10 \mathrm{mg} / \mathrm{kg} \text { every } 2 \text { weeks plus } \\
\text { paclitaxel } 90 \mathrm{mg} / \mathrm{m}^{2} \text { (days I, } 8, \mathrm{I} \text { ) every } \\
4 \text { weeks; bevacizumab } 10 \mathrm{mg} / \mathrm{kg} \text { every } \\
2 \text { weeks plus cyclophosphamide } 50 \mathrm{mg} / \\
\text { capecitabine } 3 \times 500 \mathrm{mg} \text { daily }\end{array}$ & $\begin{array}{l}\text { Incidence of prespecified grade } 3-5 \\
\text { adverse events occurring during } \\
\text { the trial or within } 30 \text { days of the } \\
\text { last treatment, regardless of the } \\
\text { causal relationship to the trial drug }\end{array}$ & $\begin{array}{l}\text { Objective response rate, disease } \\
\text { control rate, progression-free survival, } \\
\text { overall survival, other adverse events, } \\
\text { quality of life, pharmacoeconomics }\end{array}$ \\
\hline TURANDOT & $\begin{array}{l}\text { Bevacizumab } 10 \mathrm{mg} / \mathrm{kg} \text { (day I, I5) plus } \\
\text { paclitaxel } 90 \mathrm{mg} / \mathrm{m}^{2} \text { (days I, 8, I5) every } \\
4 \text { weeks; bevacizumab I5 mg/kg (day I) } \\
\text { plus capecitabine I,000 mg/m² twice daily } \\
\text { (days I-I4) every } 3 \text { weeks }\end{array}$ & Overall survival & $\begin{array}{l}\text { Proportion of patients achieving an } \\
\text { overall response, progression-free } \\
\text { survival, time to response, duration of } \\
\text { response, time to treatment failure, } \\
\text { safety, patient-reported outcomes }\end{array}$ \\
\hline CARIN & $\begin{array}{l}\text { Bevacizumab I5 mg/kg (day I) plus } \\
\text { capecitabine I,000 mg/m² twice daily } \\
\text { (days I-I4); bevacizumab I } 5 \mathrm{mg} / \mathrm{kg} \text { (day I) } \\
\text { plus capecitabine I,000 mg/m² twice daily } \\
\text { (days I-I4)/vinorelbine } 25 \mathrm{mg} / \mathrm{m}^{2} \text { (days I, 8); } \\
\text { every } 3 \text { weeks }\end{array}$ & Progression-free survival & $\begin{array}{l}\text { Overall response rate, overall survival, } \\
\text { safety }\end{array}$ \\
\hline
\end{tabular}

Abbreviations: VEGF, vascular endothelial growth factor; pVEGF, plasma VEGF. 
previous reports on this topic. ${ }^{21,22}$ It recruited both HER2negative and HER-2 positive patients, but the data were only available for the overall population rather than the HER2-negative subgroup. Therefore, the E2100 trial was excluded in this meta-analysis.

The AVADO trial was a 3-arm trial, in which HER2negative locally recurrent or metastatic breast cancer patients were randomized on a 1:1:1 basis to receive bevacizumab $7.5 \mathrm{mg} / \mathrm{kg}$ plus docetaxel $100 \mathrm{mg} / \mathrm{m}^{2}$, bevacizumab $15 \mathrm{mg} / \mathrm{kg}$ plus docetaxel $100 \mathrm{mg} / \mathrm{m}^{2}$ or placebo plus docetaxel $100 \mathrm{mg} / \mathrm{m}^{2}$ on day 1 every 3 weeks as first-line therapy. ${ }^{12}$ The evaluation of the 2 bevacizumab arms was separately compared with the control arm.

In the RIBBON-1 trial, HER2-negative locally recurrent or metastatic breast cancer patients were randomly assigned in the $2: 1$ ratio to either bevacizumab $15 \mathrm{mg} / \mathrm{kg}$ plus chemotherapy or chemotherapy alone. Chemotherapy was chosen by investigators, including capecitabine $\left(1,000 \mathrm{mg} / \mathrm{m}^{2}\right.$ oral twice daily for 14 days), taxane-based (nab-paclitaxel $260 \mathrm{mg} / \mathrm{m}^{2}$, docetaxel $75-100 \mathrm{mg} / \mathrm{m}^{2}$ ) or anthracycline-based (fluorouracil $500 \mathrm{mg} / \mathrm{m}^{2}$, epirubicin $90-100 \mathrm{mg} / \mathrm{m}^{2}$ and cyclophosphamide $500 \mathrm{mg} / \mathrm{m}^{2}$; fluorouracil $500 \mathrm{mg} / \mathrm{m}^{2}$, doxorubicin $50 \mathrm{mg} / \mathrm{m}^{2}$ and cyclophosphamide $500 \mathrm{mg} / \mathrm{m}^{2}$; doxorubicin $50-60 \mathrm{mg} / \mathrm{m}^{2}$ and cyclophosphamide $500-600 \mathrm{mg} / \mathrm{m}^{2}$; or epirubicin $90-100 \mathrm{mg} / \mathrm{m}^{2}$ and cyclophosphamide $500-600 \mathrm{mg} / \mathrm{m}^{2}$ ) regimen administered every 3 weeks. All enrolled patients were separately analyzed in the capecitabine cohort and the pooled taxane/anthracycline cohort. ${ }^{13}$

The MERiDiAN trial randomized locally recurrent or metastatic breast cancer patients to paclitaxel $90 \mathrm{mg} / \mathrm{m}^{2}$ on days 1,8 and 15 with or without bevacizumab $10 \mathrm{mg} / \mathrm{kg}$ on days 1 and 15 every 4 weeks. The co-primary endpoints were investigator-assessed PFS in the intent-to-treat (ITT) and plasma VEGF-A ${ }_{\text {high }}$ populations. ${ }^{17}$

The TABEA study compared taxanes (paclitaxel $80 \mathrm{mg} / \mathrm{m}^{2}$ on days 1,8 and 15 or docetaxel $75 \mathrm{mg} / \mathrm{m}^{2}$ on day 1 every 3 weeks) plus bevacizumab $(15 \mathrm{mg} / \mathrm{kg}$ on day 1 every 3 weeks) with (TBX group) or without capecitabine ( $1,800 \mathrm{mg} / \mathrm{m}^{2}$ daily on days $1-14$ every 3 weeks; TB group) as first-line therapy in locally advanced or metastatic breast cancer patients. ${ }^{16}$ In this meta-analysis, TBX and TB were referred to as capecitabine- and taxane-based regimens, respectively.

As to the SAKK 24/09 study, metastatic or locally recurrent inoperable HER2-negative breast cancer patients were randomized to bevacizumab $10 \mathrm{mg} / \mathrm{kg}$ every 2 weeks with either paclitaxel $90 \mathrm{mg} / \mathrm{m}^{2}$ on days 1,8 and 15 every 4 weeks or cyclophosphamide $50 \mathrm{mg}$ plus capecitabine $3 \times 500 \mathrm{mg}$ daily.
Of note, the primary endpoint was the incidence of prespecified grade $3-5$ adverse events (AEs), while PFS, OS and ORR were the secondary endpoints. ${ }^{18}$

The TURANDOT study was a non-inferiority trial that randomly assigned HER2-negative locally recurrent or metastatic breast cancer patients to either bevacizumab $10 \mathrm{mg} / \mathrm{kg}$ on days 1 and 15 plus paclitaxel $90 \mathrm{mg} / \mathrm{m}^{2}$ on days 1,8 and 15 every 4 weeks or bevacizumab $15 \mathrm{mg} / \mathrm{kg}$ on day 1 plus capecitabine $1,000 \mathrm{mg} / \mathrm{m}^{2}$ twice daily on days $1-14$ every 3 weeks. The primary endpoint was OS, and the secondary endpoints included ORR and PFS. OS was compared in both ITT and per-protocol (PP) populations. ${ }^{20}$ The OS data in the ITT and PP populations were separately included in the corresponding analysis of our study. On the other hand, the primary objective of this trial was to show non-inferior OS with bevacizumab plus capecitabine versus bevacizumab plus paclitaxel in the PP population by rejecting the null hypothesis of inferiority (HR $\geq 1.33$ ) at a one-sided significant level of 0.025 using a stratified Cox proportional hazard model $1{ }^{20}$ Therefore, the prespecified boundary for HR varied between this trial and the others, which might elicit misleading results. Accordingly, the OS data from this study were also excluded to avoid this confounding effect in this meta-analysis. Herein, there were altogether 3 types of pooled RRs for OS by using different datasets.

The CARIN trial randomized HER2-negative locally recurrent or advanced breast cancer patients to receive capecitabine $1,000 \mathrm{mg} / \mathrm{m}^{2}$ twice daily on days $1-14$ plus bevacizumab $15 \mathrm{mg} / \mathrm{kg}$ on day 1 every 3 weeks with or without vinorelbine $25 \mathrm{mg} / \mathrm{m}^{2}$ on days 1 and 8 every 3 weeks. Despite its superior nature, the significant level was set at 0.05 , two sided. ${ }^{19}$

\section{Efficacy of adding bevacizumab to chemotherapy}

In terms of the comparison between bevacizumab combined with chemotherapy and chemotherapy alone, there was significant between-study heterogeneity in the RR for PFS (heterogeneity $\chi^{2}, 27.15 ; I^{2}, 85.3 \% ; P<0.001$; Figure 1). Through the random-effects model, we found a marked improvement in PFS with the addition of bevacizumab to chemotherapy (RR, $0.869 ; 95 \% \mathrm{CI}$, 0.772-0.977; $P=0.019$; Figure 1). On the other hand, no significant between-study heterogeneity was observed in both RR for OS (heterogeneity $\chi^{2}, 3.12 ; I^{2}, 0.0 \% ; P=0.538$; Figure S2) and OR for ORR (heterogeneity $\chi^{2}, 5.03 ; I^{2}$, $20.5 \% ; P=0.284$; Figure S3). The fixed-effects model demonstrated that bevacizumab elicited great benefit in ORR 


\begin{tabular}{|c|c|c|c|c|c|}
\hline Author & Study & Regimen & $\begin{array}{l}\text { Publication } \\
\text { year }\end{array}$ & $\operatorname{RR}(95 \% \mathrm{Cl})$ & $\begin{array}{l}\% \\
\text { weight }\end{array}$ \\
\hline Miles et al ${ }^{12}$ & AVADO & $\mathrm{B} 7.5+\mathrm{DOC}$ vs PLA + DOC & 2010 & $1.00(0.95,1.06)$ & 25.33 \\
\hline Miles et al ${ }^{12}$ & AVADO & $B 15+D O C$ vs PLA + DOC & 2010 & $0.98(0.92,1.04)$ & 25.14 \\
\hline Miles et al ${ }^{17}$ & MERIDIAN & $B+P A C$ vs $P L A+P A C$ & 2017 & $0.92(0.81,1.04)$ & 20.44 \\
\hline Robert et al ${ }^{13}$ & RIBBON-1 & $\mathrm{B}+\mathrm{CAP}$ vs $\mathrm{PLA}+\mathrm{CAP}$ & 2011 & $0.69(0.56,0.85)$ & 14.95 \\
\hline Robert et al ${ }^{13}$ & RIBBON-1 & $\begin{array}{l}\text { B + TAX/ANTHRA vs } \\
\text { PLA + TAX/ANTHRA }\end{array}$ & 2011 & $0.64(0.52,0.79)$ & 14.14 \\
\hline \multicolumn{4}{|c|}{ Overall $\left(I^{2}=85.3 \%, P=0.000\right)$} & $0.87(0.77,0.98)$ & 100 \\
\hline & & & 0.516 & 1.94 & \\
\hline
\end{tabular}

Figure I Forest plot of RR for the association between the addition of bevacizumab to chemotherapy and progression-free survival in human epidermal growth factor receptor 2-negative locally recurrent or metastatic breast cancer patients.

Notes: The size of the square box is proportional to the weight that each study contributes in the meta-analysis. The overall estimate and $\mathrm{Cl}$ are marked by a diamond. Symbols on the right of the solid line indicate RR $>$ I, and symbols on the left of the solid line indicate RR $<$ I. The combined RR is calculated by the random-effects model. Weights are from the random-effects analysis.

Abbreviations: B, bevacizumab; B7.5, bevacizumab $7.5 \mathrm{mg} / \mathrm{kg}$; B I5, bevacizumab $15 \mathrm{mg} / \mathrm{kg}$; CAP, capecitabine; chemo, chemotherapy; DOC, docetaxel; PAC, paclitaxel; PLA, placebo; TAX/ANTHRA, taxanes/anthracyclines; RR, risk ratio.

(OR, 0.560; 95\% CI, 0.475-0.661; $P<0.001$; Figure S3) rather than in OS (RR, 0.986; 95\% CI, 0.891-1.090; $P=0.783$; Figure S2).

\section{Efficacy of bevacizumab plus capecitabine- based chemotherapy compared with bevacizumab plus taxane-based chemotherapy}

When it came to the comparison between bevacizumab with capecitabine- and taxane-based chemotherapy, significant between-study heterogeneity failed to be discerned in the RRs for PFS (heterogeneity $\chi^{2}, 0.85 ; I^{2}, 0.0 \% ; P=0.654$; Figure S4) and OS ([excluding the OS data from the TURANDOT trial: heterogeneity $\chi^{2}, 0.05 ; I^{2}, 0.0 \% ; P=0.829$; Figure S5]; [including the OS data from the TURANDOT trial in the ITT population: heterogeneity $\chi^{2}, 0.17 ; I^{2}, 0.0 \% ; P=0.918$; Figure S6]; [including the OS data from the TURANDOT trial in the PP population: heterogeneity $\chi^{2}, 0.10 ; I^{2}, 0.0 \% ; P=0.951$; Figure S7]) as well as in the OR for ORR (heterogeneity $\chi^{2}, 1.31 ; I^{2}, 0.0 \% ; P=0.519$; Figure S8). Therefore, the fixedeffects model was used to analyze the data, and a deleterious effect of bevacizumab plus capecitabine-based chemotherapy on PFS (RR, 1.190; 95\% CI, 1.103-1.283; $P<0.001$; Figure S4) and ORR (OR, 1.897; 95\% CI, 1.535-2.344; $P<0.001$; Figure S8) compared with bevacizumab plus taxane-based regimen was found. Intriguingly, absolute gains in ORR and PFS translated into OS benefit when the data of the TURANDOT trial in the PP population were included (RR, 1.108; 95\% CI, 1.005-1.221; $P=0.040$; Figure S7). However, these gains in ORR and PFS were lost no matter whether the data from the TURANDOT trial were excluded (RR, 1.139; 95\% CI, 0.880-1.474; $P=0.322$; Figure S5), or its ITT population data were included (RR, 1.091; 95\% CI, 0.992-1.201; $P=0.074$; Figure S6).

\section{Efficacy of bevacizumab-based doublet therapy compared with bevacizumab- based triplet therapy}

There was significant between-study heterogeneity in both RR for PFS (heterogeneity $\chi^{2}, 8.43 ; I^{2}, 76.3 \% ; P=0.015$; Figure S9) and OR for ORR (heterogeneity $\chi^{2}, 6.80 ; I^{2}, 70.6 \%$; $P=0.033$; Figure S10) rather than in the RR for OS (heterogeneity $\chi^{2}, 2.23 ; I^{2}, 10.4 \% ; P=0.327$; Figure 2 ). Through the random-effects model, bevacizumab-based triplet therapy did not significantly improve the PFS (RR, 1.046; 95\% CI, 0.856-1.279; $P=0.658$; Figure S9) or ORR (OR, 0.697; 95\% CI, 0.459-1.058; $P=0.090$; Figure S10) when compared with bevacizumab-based doublet therapy. Similarly, no statistical significance was observed for $\mathrm{OS}$ with the random-effects model (RR, 0.951; 95\% CI, 0.864-1.048; $P=0.311$; Figure 2).

\section{Publication bias and sensitivity analysis}

To assess the association between the addition of bevacizumab to chemotherapy and various clinical outcomes in 


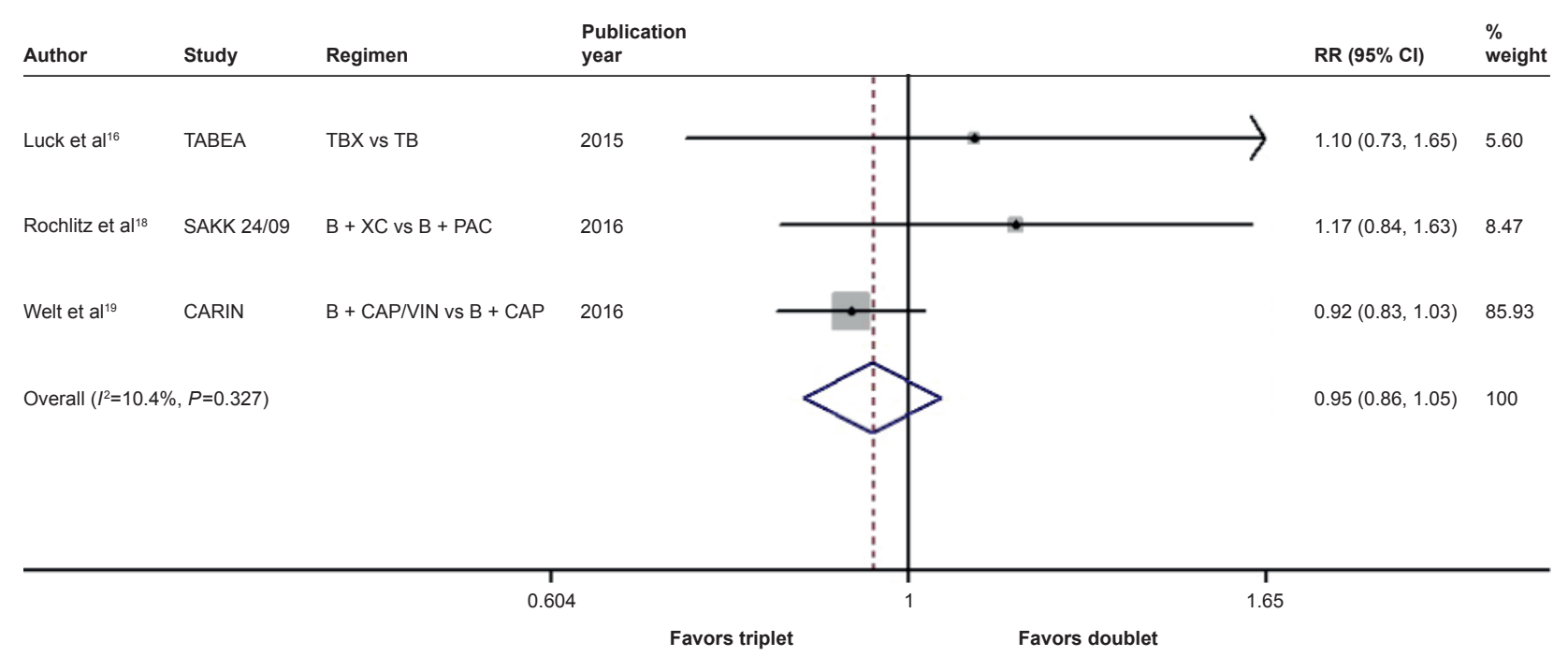

Figure 2 Forest plot of RR for the association between bevacizumab plus different numbers of chemotherapy agents and overall survival in human epidermal growth factor receptor 2-negative locally recurrent or metastatic breast cancer patients.

Notes: The size of the square box is proportional to the weight that each study contributes in the meta-analysis. The overall estimate and $\mathrm{Cl}$ are marked by a diamond. Symbols on the right of the solid line indicate RR $>$ I, and symbols on the left of the solid line indicate RR $<\mathrm{I}$. The combined RR is calculated by the fixed-effects model. Abbreviations: B, bevacizumab; CAP, capecitabine; PAC, paclitaxel; RR, risk ratio; TB, taxane/bevacizumab; TBX, taxane/bevacizumab/capecitabine; VIN, vinorelbine; XC, capecitabine/cyclophosphamide.

HER2-negative locally recurrent or metastatic breast cancer patients, either graphic inspection of funnel plots or quantitative evaluation using Begg's test indicated the absence of publication bias in OS and ORR but not for PFS ( $P=0.014)$. As to the studies evaluating the efficacy of bevacizumab plus different types or different numbers of chemotherapy agents, no publication bias was detected with either graphic inspection of funnel plots or quantitative evaluation of Begg's test in PFS, OS and ORR (data not shown). The sensitivity analyses clarified for each comparison that no individual study affected the overall RRs for PFS and OS as well as the overall ORs for ORR, because omission of any single study made no material difference.

\section{Discussion}

This meta-analysis is, to the best of our knowledge, the largest and latest study focusing on how to optimize the treatment of bevacizumab as first-line therapy in HER2-negative advanced breast cancer patients.

Our findings indicated that bevacizumab plus chemotherapy significantly improved the PFS and ORR, compared with chemotherapy alone. However, no significant advantage in OS was observed, which was similar to the results in each individual trial. Although the OS is regarded as a gold standard of endpoints and PFS as a surrogate endpoint in metastatic breast cancer, debates still continue for the importance of PFS. ${ }^{23-25}$ Advocates of OS argue that no therapeutic benefit is achieved without improving OS. This is also the reason why the FDA revoked bevacizumab's approval for metastatic breast cancer. Using OS instead of PFS as a primary endpoint is relatively difficult and expensive in enrolling the patients and completing the study. Furthermore, it is clinically meaningful to get details on whether certain interventions are capable of delaying disease progression and improving quality of life, which is generally presented by PFS. On the other hand, patients in the control arm were admitted to cross over to bevacizumab after progression in some clinical trials, ${ }^{12,13}$ which might compromise and underestimate the OS benefit of bevacizumab. Additionally, OS is normally confounded by various post-protocol factors such as subsequent treatments. ${ }^{23}$ By this token, advocates of PFS argue that PFS as a primary endpoint has its own merit and plays an important role in the evaluation of a new therapy for metastatic breast cancer, while it is not suitable for a promising agent to attach too much importance on OS.

Notwithstanding the ongoing arguments, researchers have long expected that substantial OS benefit could be obtained from bevacizumab-based regimens by identifying subgroups with specific biomarkers. A meta-analysis, which focused on the first-line bevacizumab therapy, revealed no significant improvement for OS in the triple-negative subgroup. ${ }^{22}$ On the other hand, the subsequent retrospective biomarker analysis of the AVADO trial revealed that higher plasma concentration of either VEGF-A or VEGFR-2 was associated with more benefit from bevacizumab irrespective of the bevacizumab dose. ${ }^{26}$ Unfortunately, the MERiDiAN trial, which was the first study to prospectively evaluate plasma VEGF-A, failed to verify the predictive effect of VEGF-A. ${ }^{17}$ 
Furthermore, when the available samples from the AVADO trial were reassessed by using different VEGF assays, the predictive value of plasma VEGF-A disappeared. ${ }^{27}$ Collectively, there is no solid evidence to support any biomarker as a predictive factor of bevacizumab efficacy.

This meta-analysis also demonstrated that bevacizumab combined with taxane-based chemotherapy greatly improved the PFS and ORR when compared with bevacizumab plus capecitabine-based regimen. Since the OS analysis of the TURANDOT trial was quite different from that of the other eligible trials, we separately pooled the RRs by excluding the data from the TURANDOT trial and including its data in the PP or ITT population. Only when its data in the PP population were included, did the OS comparison between the 2 groups exhibit statistical significance. Nevertheless, it is necessary for us to be aware of the prespecified boundary for HR in the TURANDOT trial. Given this situation, such advantage has to be interpreted with caution. If we take a close look at the OS data of each included trial, it is obvious that no significant OS benefit was verified in all but one of the included randomized phase III studies. The TURANDOT trial was the first study to compare bevacizumab plus paclitaxel and bevacizumab plus capecitabine. ${ }^{20}$ Before this study, these 2 bevacizumab-containing regimens, compared with chemotherapy alone, had both revealed superior PFS and ORR in the previous reports. ${ }^{10,13,17}$ Unfortunately, the oncologists had no idea whether patient tolerability could be improved by bevacizumab plus capecitabine without compromising the OS in comparison with bevacizumab plus paclitaxel at that time, so they might have been stuck in a dilemma between these two regimens. The TURANDOT trial was conducted to tackle this dilemma. Its final OS analysis met the primary endpoint of the trial, that is, the criterion for non-inferiority in the stratified analysis of the PP population. This finding was also supported by the stratified OS analysis of the ITT population despite the inferiority of bevacizumab plus capecitabine to bevacizumab plus paclitaxel for PFS. ${ }^{10}$ Therefore, the TURANDOT trial provides the evidence that bevacizumab with either paclitaxel or capecitabine has comparable OS in the first-line setting for HER2-negative locally recurrent or metastatic breast cancer patients. Besides, the SAKK 24/09 trial also gives further support for the combined effect of capecitabine with bevacizumab. Although the primary endpoint in this trial was the incidence of prespecified grade 3-5 AEs instead of ORR, PFS and OS, its results might also offer some clues. The SAKK 24/09 trial showed no statistical significance between bevacizumab plus paclitaxel and bevacizumab plus metronomic capecitabine-cyclophosphamide in terms of ORR, PFS and OS. ${ }^{18}$
Taken together, these findings clarify that the combination of bevacizumab and capecitabine may function as a valid firstline treatment option. In Europe, this regimen, along with bevacizumab plus paclitaxel, has been identified as one of the first-line indications for HER2-negative locally recurrent or metastatic breast cancer patients. ${ }^{28}$ However, bevacizumab combined with paclitaxel is the only regimen listed in the latest version of the National Comprehensive Cancer Network Clinical Practice Guidelines in Oncology for Breast Cancer. ${ }^{29}$ Furthermore, Delaloge et al demonstrated on the basis of a large-scale real-life setting database that HER2-negative metastatic breast cancer patients who received paclitaxel plus bevacizumab as first-line chemotherapy had a significantly better OS and PFS than those receiving paclitaxel alone. ${ }^{30}$ With the accumulation of evidence, we will get a clearer picture of how to choose the preferable chemotherapy partner of bevacizumab.

Last but not the least, when it came to the comparison between the doublet versus the triplet, the addition of a third agent appears to make no sense in the improvement of clinical outcomes. Similar findings have also been reported. The BCIRG 007 trial is a phase III randomized study conducted to compare docetaxel/carboplatin/trastuzumab (TCH) with docetaxel/trastuzumab (TH) as first-line therapy in HER2amplified metastatic breast cancer. Interestingly, adding carboplatin to $\mathrm{TH}$ did not elicit any significant improvement in time to progression, response rate or OS. ${ }^{31}$ In many cases, therefore, less is more.

\section{Conclusion}

This meta-analysis indicated that the combination of bevacizumab and chemotherapy as first-line treatment significantly improved the PFS and ORR in locally recurrent or metastatic breast cancer patients. Greater benefits in PFS and ORR were observed in bevacizumab plus taxane-based regimens compared with bevacizumab plus capecitabine-based ones. In view of the non-inferiority for OS, however, increasing evidence supports the use of bevacizumab plus capecitabine as a preferable first-line option in the USA. Nevertheless, it is far from the end of the story. Additional studies are necessary to further optimize the first-line treatment of bevacizumab.

\section{Acknowledgment}

This study was supported by the grants from the National Natural Science Foundation of China (81302302), the Doctoral Programs Foundation of the Ministry of Education of China (20120071120105) and the Shanghai Natural Science Foundation (13ZR1452800). 


\section{Author contributions}

WY and JL conceived and designed the work. CL and AX performed the publication search and the statistical analysis. $\mathrm{XC}$ and KY extracted the data. All authors interpreted the results. CL and AX wrote the manuscript draft. All authors participated in the revision. All authors approved the final version.

\section{Disclosure}

The authors report no conflicts of interest in this work.

\section{References}

1. Alvarez RH. Present and future evolution of advanced breast cancer therapy. Breast Cancer Res. 2010;12(Suppl 2):S1.

2. Linderholm B, Grankvist K, Wilking N, Johansson M, Tavelin B, Henriksson R. Correlation of vascular endothelial growth factor content with recurrences, survival, and first relapse site in primary node-positive breast carcinoma after adjuvant treatment. J Clin Oncol. 2000;18(7):1423-1431.

3. McLeskey SW, Tobias CA, Vezza PR, Filie AC, Kern FG, Hanfelt J. Tumor growth of FGF or VEGF transfected MCF-7 breast carcinoma cells correlates with density of specific microvessels independent of the transfected angiogenic factor. Am J Pathol. 1998;153(6):1993-2006.

4. Uzzan B, Nicolas P, Cucherat M, Perret GY. Microvessel density as a prognostic factor in women with breast cancer: a systematic review of the literature and meta-analysis. Cancer Res. 2004;64(9):2941-2955.

5. Weidner N, Folkman J, Pozza F, et al. Tumor angiogenesis: a new significant and independent prognostic indicator in early-stage breast carcinoma. J Natl Cancer Inst. 1992;84(24):1875-1887.

6. Bonapace L, Coissieux MM, Wyckoff J, et al. Cessation of CCL2 inhibition accelerates breast cancer metastasis by promoting angiogenesis. Nature. 2014;515(7525):130-133.

7. Sossey-Alaoui K, Pluskota E, Davuluri G, et al. Kindlin-3 enhances breast cancer progression and metastasis by activating Twist-mediated angiogenesis. FASEB J. 2014;28(5):2260-2271.

8. Kong W, He L, Richards EJ, et al. Upregulation of miRNA-155 promotes tumour angiogenesis by targeting VHL and is associated with poor prognosis and triple-negative breast cancer. Oncogene. 2014;33(6): 679-689.

9. Scott LJ. Bevacizumab: in first-line treatment of metastatic breast cancer. Drugs. 2007;67(12):1793-1799.

10. Miller K, Wang M, Gralow J, et al. Paclitaxel plus bevacizumab versus paclitaxel alone for metastatic breast cancer. $N$ Engl J Med. 2007; 357(26):2666-2676.

11. European Medicines Agency: European Medicines Agency completes its review of Avastin used in breast cancer [Press release 16/12/2010], 2010 .

12. Miles DW, Chan A, Dirix LY, et al. Phase III study of bevacizumab plus docetaxel compared with placebo plus docetaxel for the first-line treatment of human epidermal growth factor receptor 2-negative metastatic breast cancer. J Clin Oncol. 2010;28(20):3239-3247.

13. Robert NJ, Dieras V, Glaspy J, et al. RIBBON-1: randomized, doubleblind, placebo-controlled, phase III trial of chemotherapy with or without bevacizumab for first-line treatment of human epidermal growth factor receptor 2-negative, locally recurrent or metastatic breast cancer. J Clin Oncol. 2011;29(10):1252-1260.

14. Moher D, Cook DJ, Eastwood S, et al. Improving the quality of reports of meta-analyses of randomised controlled trials: the QUOROM statement. Quality of Reporting of Meta-analyses. Lancet. 1999;354(9193): 1896-1900.

15. Higgins JP, Thompson SG. Quantifying heterogeneity in a metaanalysis. Stat Med. 2002;21(11):1539-1558.
16. Luck HJ, Lubbe K, Reinisch M, et al. Phase III study on efficacy of taxanes plus bevacizumab with or without capecitabine as first-line chemotherapy in metastatic breast cancer. Breast Cancer Res Treat. 2015;149(1):141-149.

17. Miles D, Cameron D, Bondarenko I, et al. Bevacizumab plus paclitaxel versus placebo plus paclitaxel as first-line therapy for HER2-negative metastatic breast cancer (MERiDiAN): a doubleblind placebo-controlled randomised phase III trial with prospective biomarker evaluation. Eur J Cancer. 2017;70:146-155.

18. Rochlitz C, Bigler M, von Moos R, et al. SAKK 24/09: safety and tolerability of bevacizumab plus paclitaxel versus bevacizumab plus metronomic cyclophosphamide and capecitabine as first-line therapy in patients with HER2-negative advanced stage breast cancer - a multicenter, randomized phase III trial. BMC Cancer. 2016;16:780.

19. Welt A, Marschner N, Lerchenmueller C, et al. Capecitabine and bevacizumab with or without vinorelbine in first-line treatment of HER2/ neu-negative metastatic or locally advanced breast cancer: final efficacy and safety data of the randomised, open-label superiority phase 3 CARIN trial. Breast Cancer Res Treat. 2016;156(1):97-107.

20. Zielinski C, Lang I, Inbar M, et al. Bevacizumab plus paclitaxel versus bevacizumab plus capecitabine as first-line treatment for HER2-negative metastatic breast cancer (TURANDOT): primary endpoint results of a randomised, open-label, non-inferiority, phase 3 trial. Lancet Oncol. 2016;17(19):1230-1239.

21. Fang Y, Qu X, Cheng B, et al. The efficacy and safety of bevacizumab combined with chemotherapy in treatment of HER2-negative metastatic breast cancer: a meta-analysis based on published phase III trials. Tumour Biol. 2015;36(3):1933-1941.

22. Miles DW, Dieras V, Cortes J, Duenne AA, Yi J, O’Shaughnessy J. First-line bevacizumab in combination with chemotherapy for HER2negative metastatic breast cancer: pooled and subgroup analyses of data from 2447 patients. Ann Oncol. 2013;24(11):2773-2780.

23. Robert NJ. Overall survival in metastatic breast cancer: always our quest but not necessarily a primary endpoint. Breast Cancer Res Treat. 2010;122(1):9-10.

24. Sharma SP. Avastin saga reveals debate over clinical trial endpoints. J Natl Cancer Inst. 2012;104(11):800-801.

25. Raphael J, Verma S. Overall survival (OS) endpoint: an incomplete evaluation of metastatic breast cancer (MBC) treatment outcome. Breast Cancer Res Treat. 2015;150(3):473-478.

26. Miles DW, de Haas SL, Dirix LY, et al. Biomarker results from the AVADO phase 3 trial of first-line bevacizumab plus docetaxel for HER2-negative metastatic breast cancer. Br J Cancer. 2013;108(5): 1052-1060.

27. Bais C, Rabe C, Wild N, et al. Comprehensive reassessment of plasma VEGFA (pVEGFA) as a candidate predictive biomarker for bevacizumab (Bv) in 13 pivotal trials (seven indications). J Clin Oncol. 2014; 32 (suppl 15):3040.

28. European Medicines Agency: Assessment Report For Avastin (bevacizumab) 2011.

29. Network NCC. National Comprehensive Cancer Network (NCCN) Clinical Practice Guidelines in Oncology for Breast cancer (Version 2. 2017), 2017.

30. Delaloge S, Pérol D, Brain E, et al. Overall survival of patients with HER2-negative metastatic breast cancer treated with a first-line paclitaxel with or without bevacizumab in real-life setting: results of a multicenter national observational study. 2016 ASCO Annual Meeting. McCormick Place, Chicago, Illinois. J Clin Oncol. 2016;34:(Suppl; abstr 1013).

31. Valero V, Forbes J, Pegram MD, et al. Multicenter phase III randomized trial comparing docetaxel and trastuzumab with docetaxel, carboplatin, and trastuzumab as first-line chemotherapy for patients with HER2gene-amplified metastatic breast cancer (BCIRG 007 study): two highly active therapeutic regimens. J Clin Oncol. 2011;29:149-156. 


\section{Supplementary materials}

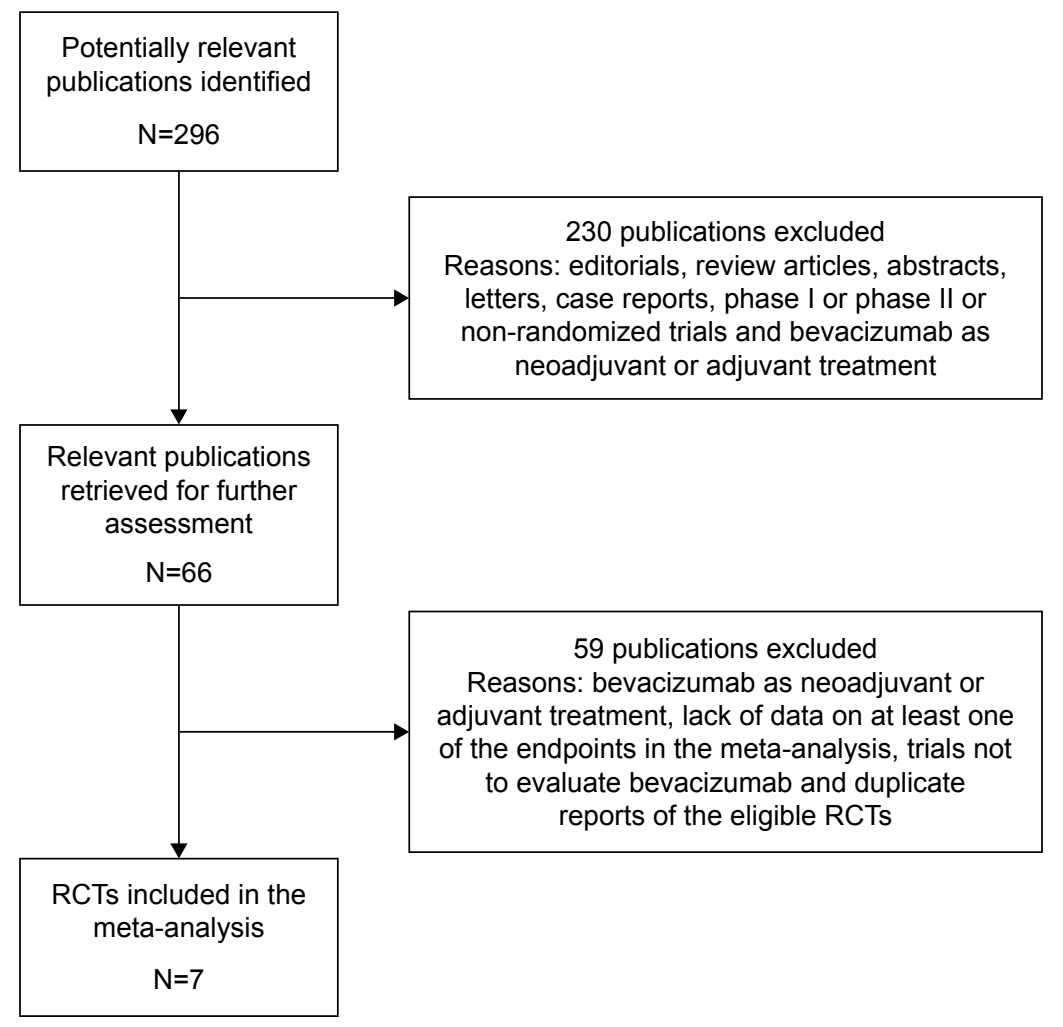

Figure SI Selection process for randomized controlled clinical trials included in the meta-analysis.

Abbreviation: RCTs, randomized controlled trials.

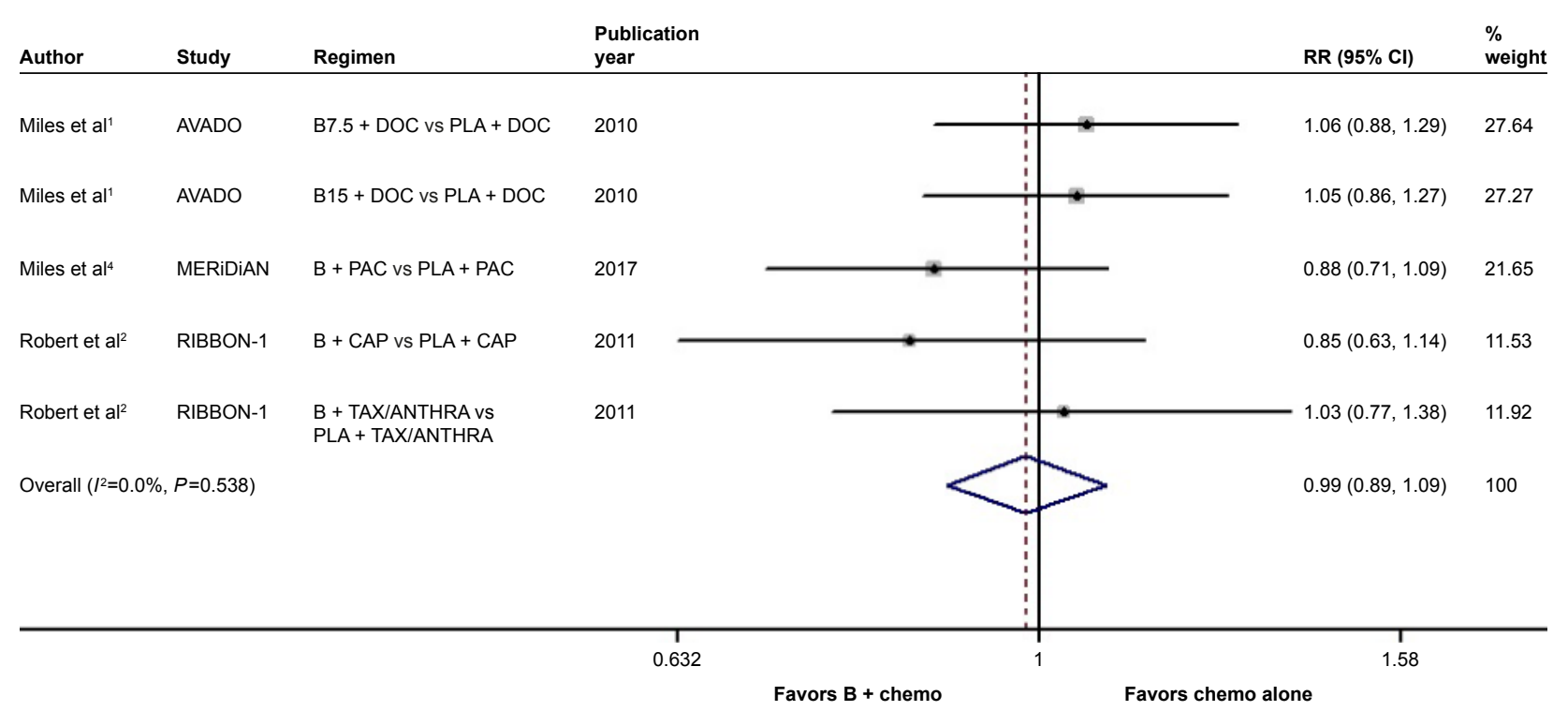

Figure S2 Forest plot of RR for the association between the addition of bevacizumab to chemotherapy and overall survival in human epidermal growth factor receptor 2-negative locally recurrent or metastatic breast cancer patients.

Notes: The size of the square box is proportional to the weight that each study contributes in the meta-analysis. The overall estimate and $\mathrm{Cl}$ are marked by a diamond. Symbols on the right of the solid line indicate RR $>$ I, and symbols on the left of the solid line indicate RR $<$ I. The combined RR is calculated by the fixed-effects model. Abbreviations: B, bevacizumab; B7.5, bevacizumab $7.5 \mathrm{mg} / \mathrm{kg}$; BI5, bevacizumab $15 \mathrm{mg} / \mathrm{kg}$; CAP, capecitabine; chemo, chemotherapy; DOC, docetaxel; PAC, paclitaxel; PLA, placebo; RR, risk ratio; TAX/ANTHRA, taxanes/anthracyclines. 


\begin{tabular}{|c|c|c|c|c|c|}
\hline Author & Study & Regimen & $\begin{array}{l}\text { Publication } \\
\text { year }\end{array}$ & OR $(95 \% \mathrm{Cl})$ & $\begin{array}{l}\% \\
\text { weight }\end{array}$ \\
\hline Miles et al ${ }^{1}$ & AVADO & $\mathrm{B} 7.5+\mathrm{DOC}$ vs PLA + DOC & 2010 & $0.70(0.49,1.00)$ & 18.76 \\
\hline Miles et al ${ }^{1}$ & AVADO & $\mathrm{B} 15+\mathrm{DOC}$ vs PLA + DOC & 2010 & $0.49(0.34,0.70)$ & 21.68 \\
\hline Miles et $\mathrm{al}^{4}$ & MERIDIAN & $B+P A C$ vs $P L A+P A C$ & 2017 & $0.42(0.29,0.61)$ & 22.56 \\
\hline Robert et al ${ }^{2}$ & RIBBON-1 & $B+C A P$ vs $P L A+C A P$ & 2011 & $0.58(0.38,0.87)$ & 16.31 \\
\hline Robert et $\mathrm{al}^{2}$ & RIBBON-1 & $\begin{array}{l}\text { B + TAX/ANTHRA vs } \\
\text { PLA + TAX/ANTHRA }\end{array}$ & 2011 & $0.64(0.45,0.91)$ & 20.68 \\
\hline \multicolumn{4}{|c|}{ Overall $\left(I^{2}=20.5 \%, P=0.284\right)$} & $0.56(0.48,0.66)$ & 100 \\
\hline & & & 0.291 & 3.44 & \\
\hline
\end{tabular}

Figure S3 Forest plot of OR for the association between the addition of bevacizumab to chemotherapy and objective response rate in human epidermal growth factor receptor 2-negative locally recurrent or metastatic breast cancer patients.

Notes: The size of the square box is proportional to the weight that each study contributes in the meta-analysis. The overall estimate and $\mathrm{Cl}$ are marked by a diamond. Symbols on the right of the solid line indicate $O R>I$, and symbols on the left of the solid line indicate OR $<$ I. The combined OR is calculated by the fixed-effects model. Abbreviations: B, bevacizumab; B7.5, bevacizumab $7.5 \mathrm{mg} / \mathrm{kg}$; BI5, bevacizumab $15 \mathrm{mg} / \mathrm{kg}$; chemo, chemotherapy; CAP, capecitabine; DOC, docetaxel; OR, odds ratio; PAC, paclitaxel; PLA, placebo; TAXIANTHRA, taxanes/anthracyclines.

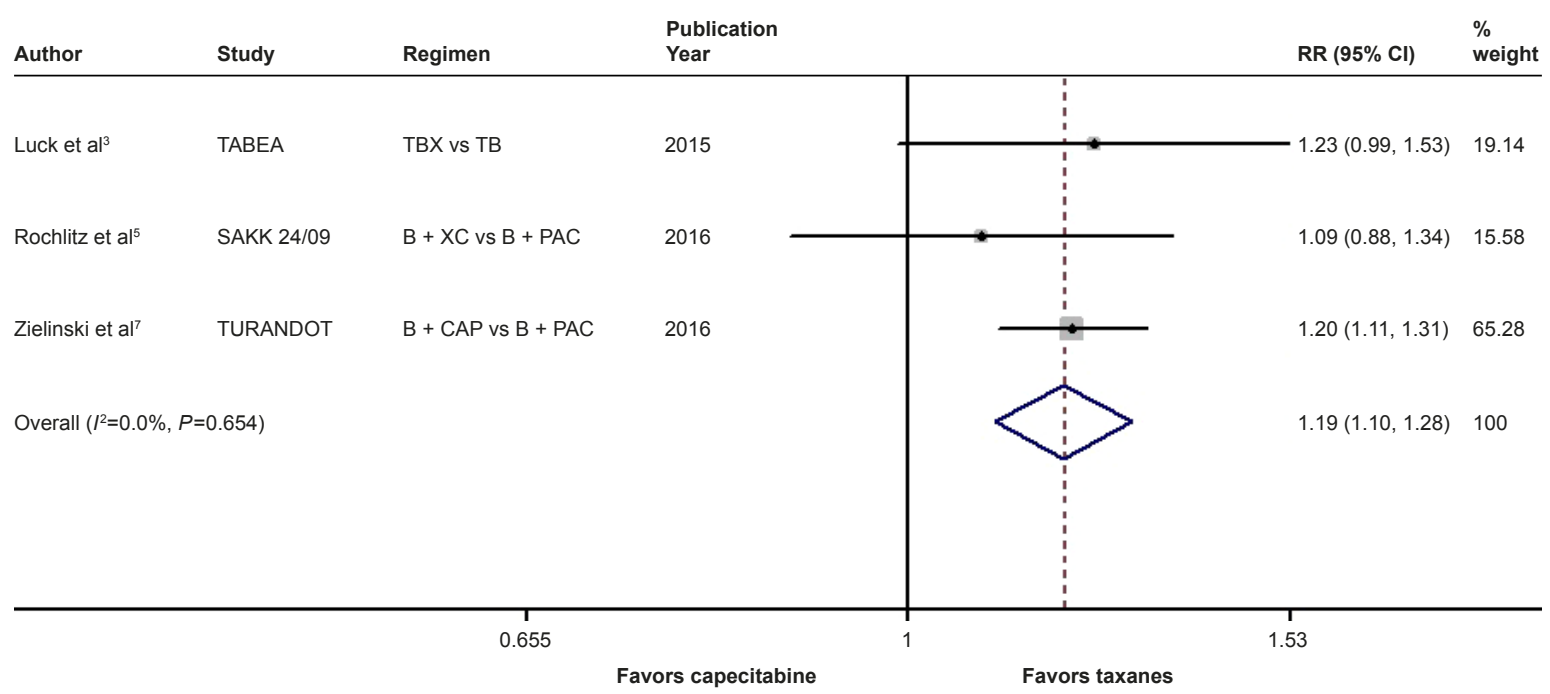

Figure S4 Forest plot of RR for the association between bevacizumab plus different types of chemotherapy agents and progression-free survival in human epidermal growth factor receptor 2-negative locally recurrent or metastatic breast cancer patients.

Notes: The size of the square box is proportional to the weight that each study contributes in the meta-analysis. The overall estimate and $\mathrm{Cl}$ are marked by a diamond. Symbols on the right of the solid line indicate RR $>$ I, and symbols on the left of the solid line indicate RR $<$ I. The combined RR is calculated by the fixed-effects model. Abbreviations: B, bevacizumab; CAP, capecitabine; PAC, paclitaxel; RR, risk ratio; TB, taxane/bevacizumab; TBX, taxane/bevacizumab/capecitabine; XC, capecitabine/ cyclophosphamide. 


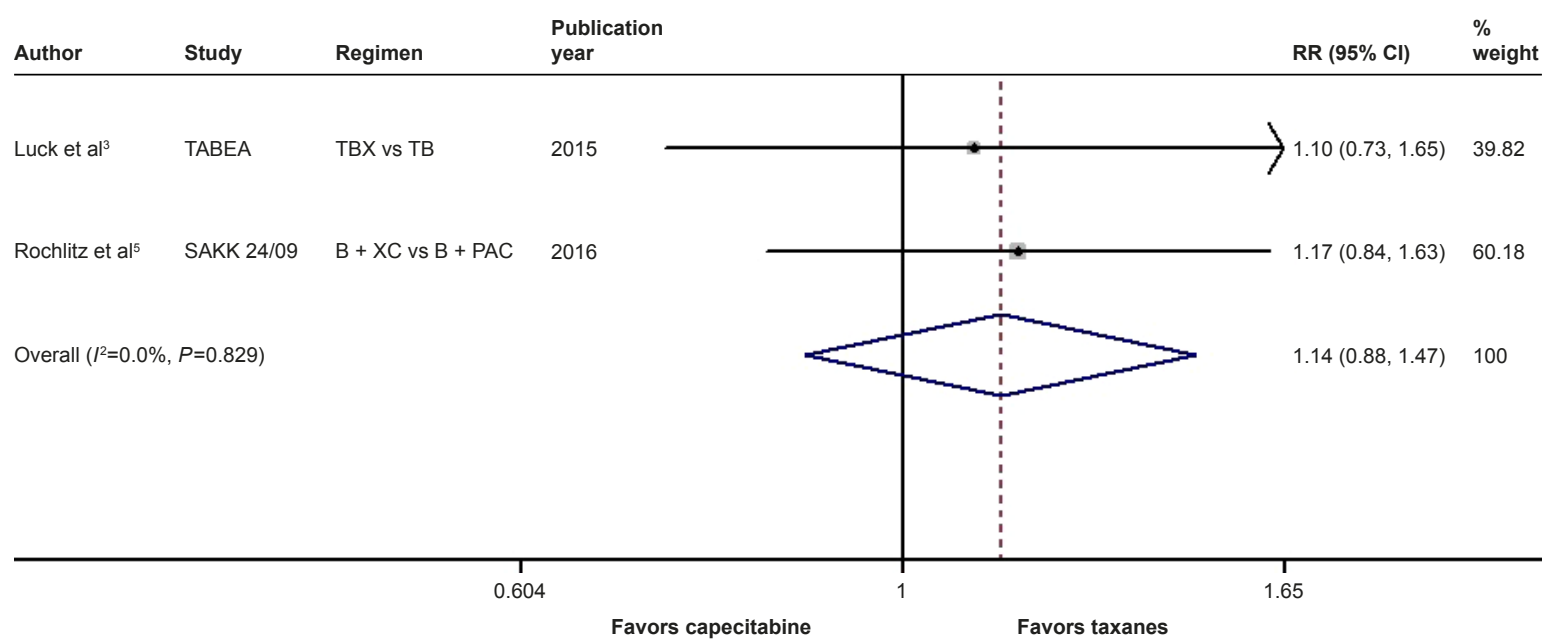

Figure S5 Forest plot of RR for the association between bevacizumab plus different types of chemotherapy agents and overall survival in human epidermal growth factor receptor 2-negative locally recurrent or metastatic breast cancer patients, excluding the data of the TURANDOT trial.

Notes: The size of the square box is proportional to the weight that each study contributes in the meta-analysis. The overall estimate and $\mathrm{Cl}$ are marked by a diamond Symbols on the right of the solid line indicate RR $>$ I, and symbols on the left of the solid line indicate $R R<I$. The combined RR is calculated by the fixed-effects model. Abbreviations: B, bevacizumab; PAC, paclitaxel; RR, risk ratio; TB, taxane/bevacizumab; TBX, taxane/bevacizumab/capecitabine; XC, capecitabine/cyclophosphamide.

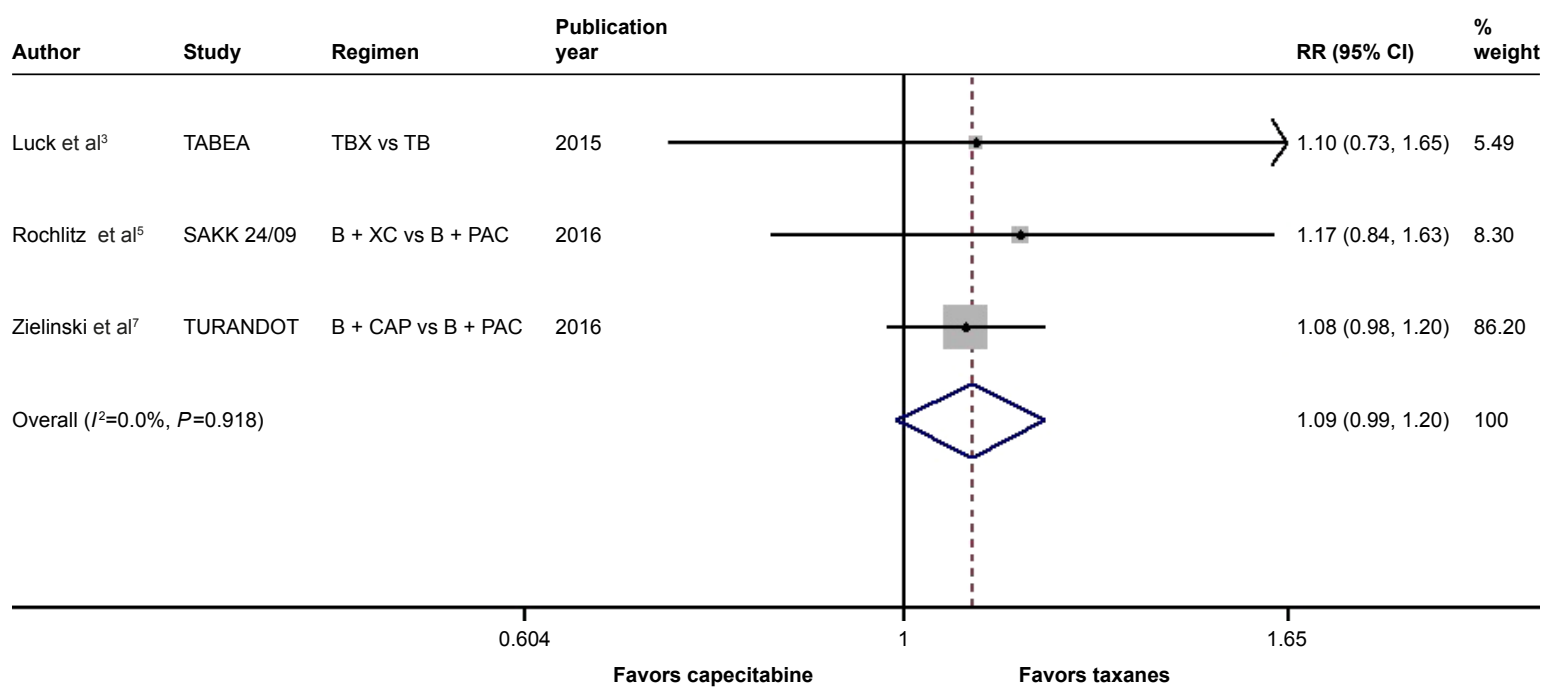

Figure S6 Forest plot of RR for the association between bevacizumab plus different types of chemotherapy agents and overall survival in human epidermal growth factor receptor 2-negative locally recurrent or metastatic breast cancer patients, including the data of the TURANDOT trial in the intent-to-treat population.

Notes: The size of the square box is proportional to the weight that each study contributes in the meta-analysis. The overall estimate and $\mathrm{Cl}$ are marked by a diamond. Symbols on the right of the solid line indicate RR $>$ I, and symbols on the left of the solid line indicate $R R<I$. The combined RR is calculated by the fixed-effects model. Abbreviations: B, bevacizumab; CAP, capecitabine; PAC, paclitaxel; RR, risk ratio; TB, taxane/bevacizumab; TBX, taxane/bevacizumab/capecitabine; XC, capecitabine/ cyclophosphamide. 


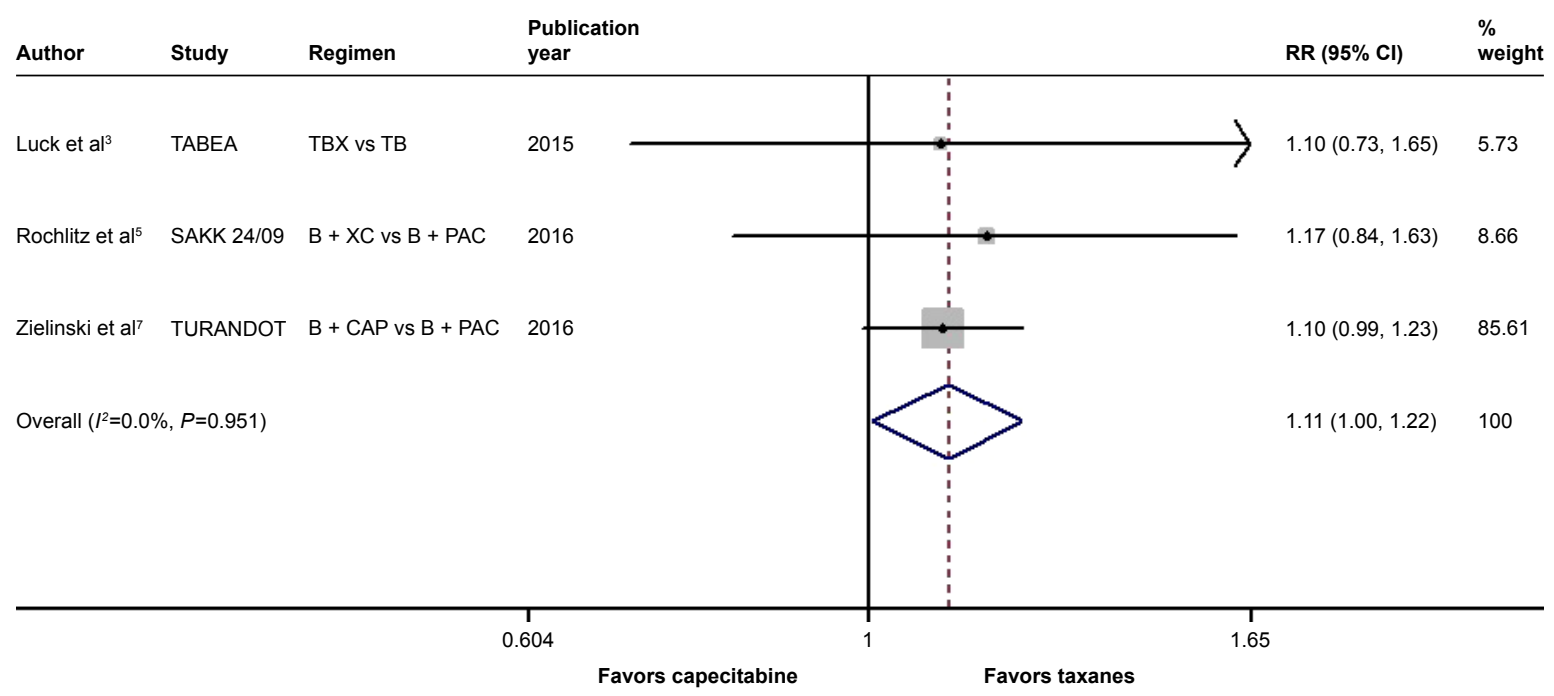

Figure S7 Forest plot of RR for the association between bevacizumab plus different types of chemotherapy agents and overall survival in human epidermal growth factor receptor 2-negative locally recurrent or metastatic breast cancer patients, including the data of the TURANDOT trial in the per-protocol population.

Notes: The size of the square box is proportional to the weight that each study contributes in the meta-analysis. The overall estimate and $\mathrm{Cl}$ are marked by a diamond. Symbols on the right of the solid line indicate RR $>I$, and symbols on the left of the solid line indicate $R R<I$. The combined RR is calculated by the fixed-effects model. Abbreviations: B, bevacizumab; CAP, capecitabine; PAC, paclitaxel; RR, risk ratio; TB, taxane/bevacizumab; TBX, taxane/bevacizumab/capecitabine; XC, capecitabine/ cyclophosphamide.

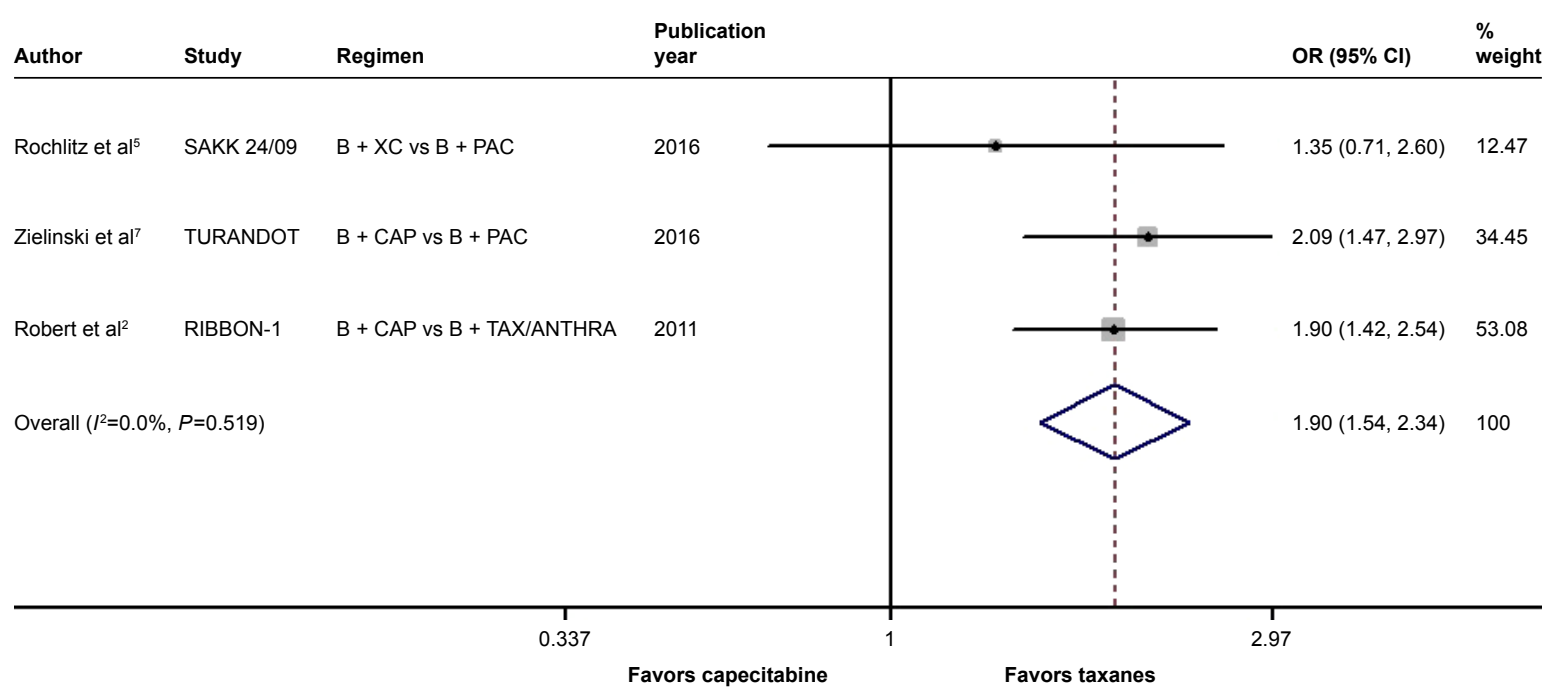

Figure S8 Forest plot of OR for the association between bevacizumab plus different types of chemotherapy agents and objective response rate in human epidermal growth factor receptor 2-negative locally recurrent or metastatic breast cancer patients.

Notes: The size of the square box is proportional to the weight that each study contributes in the meta-analysis. The overall estimate and $\mathrm{Cl}$ are marked by a diamond. Symbols on the right of the solid line indicate $O R>I$, and symbols on the left of the solid line indicate $O R<I$. The combined $O R$ is calculated by the fixed-effects model. Abbreviations: B, bevacizumab; CAP, capecitabine; OR, odds ratio; PAC, paclitaxel; TAX/ANTHRA, taxanes/anthracyclines; XC, capecitabine/cyclophosphamide. 


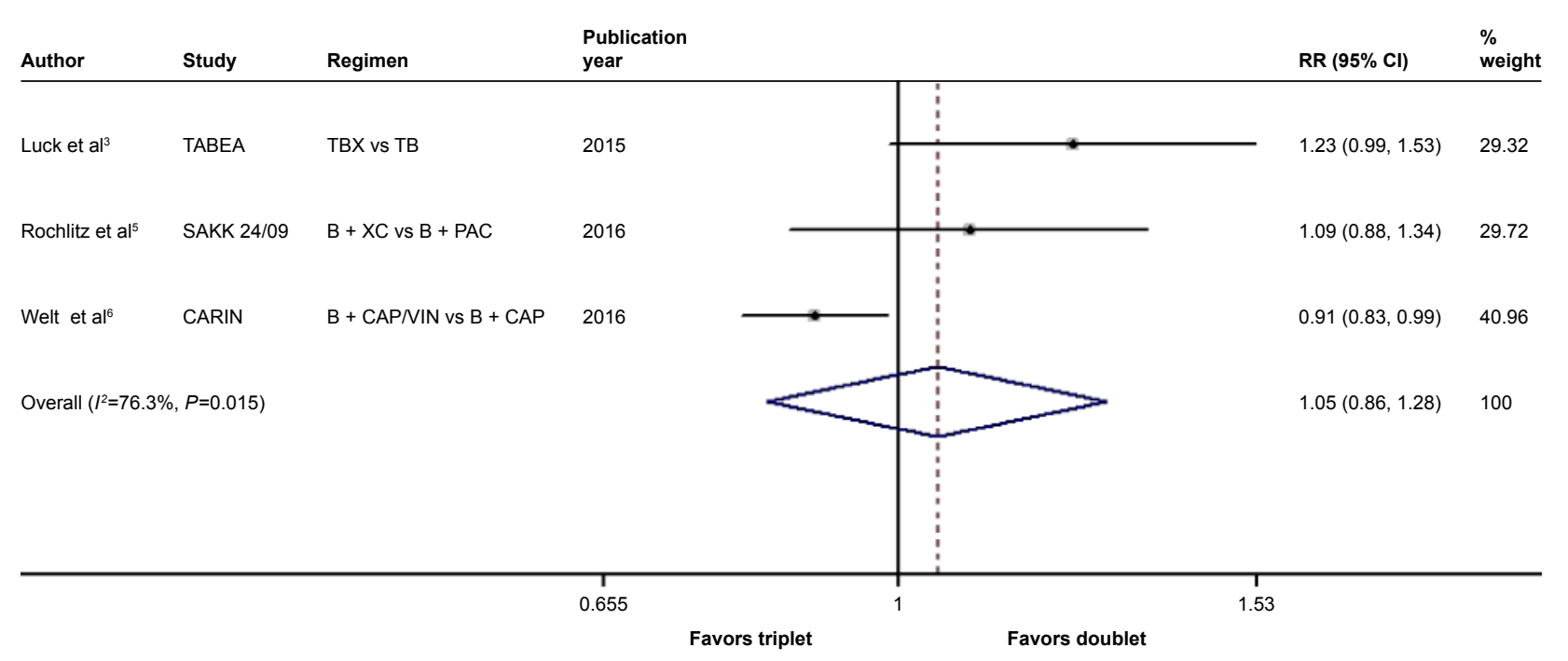

Figure S9 Forest plot of RR for the association between bevacizumab plus different numbers of chemotherapy agents and progression-free survival in human epidermal growth factor receptor 2-negative locally recurrent or metastatic breast cancer patients.

Notes: The size of the square box is proportional to the weight that each study contributes in the meta-analysis. The overall estimate and $\mathrm{Cl}$ are marked by a diamond. Symbols on the right of the solid line indicate RR $>I$, and symbols on the left of the solid line indicate RR $<$ I. The combined RR is calculated by the random-effects model. Weights are from the random-effects analysis.

Abbreviations: B, bevacizumab; CAP, capecitabine; PAC, paclitaxel; RR, risk ratio; TB, taxane/bevacizumab; TBX, taxane/bevacizumab/capecitabine; VIN, vinorelbine; XC, capecitabine/cyclophosphamide.

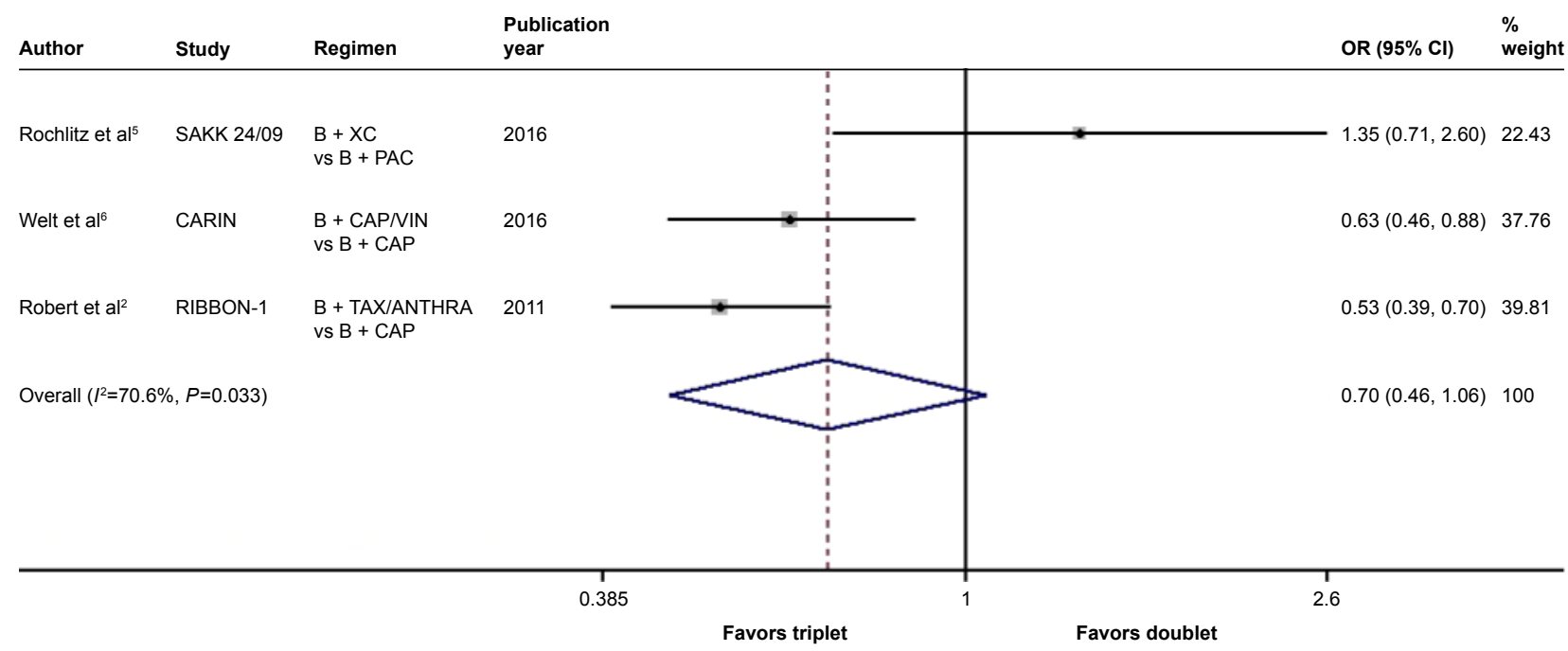

Figure SIO Forest plot of OR for the association between bevacizumab plus different numbers of chemotherapy agents and objective response rate in human epidermal growth factor receptor 2-negative locally recurrent or metastatic breast cancer patients.

Notes: The size of the square box is proportional to the weight that each study contributes in the meta-analysis. The overall estimate and $\mathrm{Cl}$ are marked by a diamond. Symbols on the right of the solid line indicate OR $>$ I, and symbols on the left of the solid line indicate OR $<$ I. The combined OR is calculated by the random-effects model. Weights are from the random-effects analysis.

Abbreviations: B, bevacizumab; CAP, capecitabine; OR, odds ratio; PAC, paclitaxel; VIN, vinorelbine; TAX/ANTHRA, taxanes/anthracyclines; XC, capecitabine/ cyclophosphamide.

\section{References}

1. Miles DW, Chan A, Dirix LY, et al. Phase III study of bevacizumab plus docetaxel compared with placebo plus docetaxel for the firstline treatment of human epidermal growth factor receptor 2-negative metastatic breast cancer. J Clin Oncol. 2010;28:3239-3247.

2. Robert NJ, Dieras V, Glaspy J, et al. RIBBON-1: randomized, double-blind, placebo-controlled, phase III trial of chemotherapy with or without bevacizumab for first-line treatment of human epidermal growth factor receptor 2-negative, locally recurrent or metastatic breast cancer. J Clin Oncol. 2011;29:1252-1260.
3. Luck HJ, Lubbe K, Reinisch M, et al. Phase III study on efficacy of taxanes plus bevacizumab with or without capecitabine as first-line chemotherapy in metastatic breast cancer. Breast Cancer Res Treat. 2015; 149:141-149.

4. Miles D, Cameron D, Bondarenko I, et al. Bevacizumab plus paclitaxel versus placebo plus paclitaxel as first-line therapy for HER2-negative metastatic breast cancer (MERiDiAN): a double-blind placebo-controlled randomised phase III trial with prospective biomarker evaluation. Eur $J$ Cancer. 2017;70:146-155. 
5. Rochlitz C, Bigler M, von Moos R, et al. SAKK 24/09: safety and tolerability of bevacizumab plus paclitaxel versus bevacizumab plus metronomic cyclophosphamide and capecitabine as first-line therapy in patients with HER2-negative advanced stage breast cancer - a multicenter, randomized phase III trial. BMC Cancer. 2016;16:780.

6. Welt A, Marschner N, Lerchenmueller C, et al. Capecitabine and bevacizumab with or without vinorelbine in first-line treatment of HER2/ neu-negative metastatic or locally advanced breast cancer: final efficacy and safety data of the randomised, open-label superiority phase 3 CARIN trial. Breast Cancer Res Treat. 2016;156:97-107.
7. Zielinski C, Lang I, Inbar M, et al. Bevacizumab plus paclitaxel versus bevacizumab plus capecitabine as first-line treatment for HER2-negative metastatic breast cancer (TURANDOT): primary endpoint results of a randomised, open-label, non-inferiority, phase 3 trial. Lancet Oncol. 2016;17:1230-1239.

\section{Publish your work in this journal}

OncoTargets and Therapy is an international, peer-reviewed, open access journal focusing on the pathological basis of all cancers, potential targets for therapy and treatment protocols employed to improve the management of cancer patients. The journal also focuses on the impact of management programs and new therapeutic agents and protocols on

\section{Dovepress}

patient perspectives such as quality of life, adherence and satisfaction. The manuscript management system is completely online and includes a very quick and fair peer-review system, which is all easy to use. Visit http://www.dovepress.com/testimonials.php to read real quotes from published authors. 